\title{
Pengembangan Media Sosialisasi Akses e-resources Berbasis Video Tutorial di Perpustakaan Universitas Gadjah Mada
}

\author{
Desy Natalia A. ${ }^{1}$ Dewi Nurhastuti ${ }^{2}$ \\ Perpustakaan Universitas Gadjah Mada \\ email: desy_fkg@ugm.ac.id
}

\begin{abstract}
Abstrak
Penelitian ini membahas pengembangan media sosialisasi akses e-resources dengan video tutorial di Perpustakaan Universitas Gadjah Mada (UGM). Tujuan penelitian ini adalah untuk mengetahui efektivitas hasil akses e-resources sivitas akademika yang menggunakan panduan video tutorial dengan yang menggunakan panduan tertulis di website Perpustakaan UGM, serta kesulitan apa saja yang ditemukan sivitas akademika UGM dalam memahami panduan video tutorial akses e-resources. Metode penelitian yang digunakan adalah penelitian deskriptif dengan metode kuantitatif. Analisis data dilakukan dengan menggunakan teknik analisis deskriptif kuantitatif, yaitu dengan menganalisis data kuantitatif yang diperoleh dari kuisioner dari sumber internal Perpustakaan UGM dan sumber eksternal Perpustakan UGM.

Hasil penelitian menunjukkan bahwa dari penilaiaan sumber internal aspek tampilan memperoleh skor sebesar 86,1\% kategori sangat layak, aspek pengoperasian sebesar 85,4\% kategori sangat layak. Sedangkan aspek kemanfaatan sebesar $88,9 \%$ kategori sangat layak. Untuk sumber eksternal Perpustakaan UGM, aspek tampilan memperoleh skor 83,4\% kategori sangat layak, aspek pengoperasian sebesar $85,3 \%$ kategori sangat layak serta aspek kemanfaatan sebesar $82,2 \%$ kategori sangat layak. Penelitian ini juga menunjukkan bahwa perencanaan pembuatan video berkaitan dengan beberapa aspek yaitu: durasi video yang akan dibuat; model video; batasan tema video konten, penambahan bookmark pada video, serta aspek sasaran konsumen yang memanfaatkan. Simpulan penelitian ini, video tutorial dinilai sangat layak oleh responden sehingga dapat digunakan sebagai sarana publikasi, pengembangan layanan, dan model kemas ulang informasi atau literasi informasi berbasis video di perpustakaan sesuai kebutuhan sivitas akademika
\end{abstract}

\section{A. PENDAHULUAN}

Menyambut era revolusi 4.0 perpustakaan dan pustakawan dituntut untuk berperan aktif, relevan dan dinamis, dan meningkatkan kompetensi sesuai dengan kebutuhan pemustaka sehingga dapat meningkatkan kualitas pembelajaran, penguatan riset, penguatan pengabdian, peningkatan jumlah publikasi dan peningkatan kualitas jurnal. Dalam menghadapi pemustaka saat ini, pustakawan berperan sebagai mitra belajar. Sehingga diperlukan kompetensi dan keterampilan dalam komunikasi dan Teknologi Informasi, bersikap professional, memberikan layanan prima, berinovasi dan kreatif dalam melakukan promosi dan sosialisasi sumber daya yang dimilikinya, salah satunya adalah sumber daya elektronik.

\author{
Kata Kunci: \\ Efektivitas \\ kemas ulang informasi \\ literasi informasi \\ video tutorial \\ e-resources \\ Perpustakaan Universitas \\ Gadjah Mada
}

Perpustakaan Universitas Gadjah Mada (UGM), melalui websitenya menginformasikan cara mengakses sumber daya elektroniknya. Salah satu hal yang dapat dapat dilakukan dalam memberikan pelayanan yang berbasis Revolusi Industri 4.0 adalah memberikan informasi layanan berupa pengembangan media sosialisasi akses e-resources berbasis video Tutorial di Perpustakaan Universitas Gadjah Mada. Hal ini dimaksudkan agar proses pengaksesan dan pembelajaran serta pendistribusian informasi kepada seluruh sivitas akademika dapat terlaksana dengan lebih efektif. Peneliti berasumsi bahwa keunggulan panduan akases e-resources berupa video tutorial di dalam penyampaian informasi adalah dapat memaksa pengguna untuk lebih berinteraksi dengan materi 
baik secara fisik dan mental. Tentu saja kemampuan memaksa ini tergantung pada seberapa efektif video instruksi tersebut mampu menarik sivitas akademika untuk menggunakannya pada saat mengakses e-resources.

Kondisi di atas melatarbelakangi peneliti untuk melakukan penelitian terkait pengembangan produk layanan berupa video tutorial dan bagaimana efektivitas hasil akses e-resources sivitas akademika yang menggunakan panduan video tutorial dengan yang menggunakan panduan tertulis akses e-resources di website Perpustakaan UGM dan kesulitan apa saja yang ditemukan sivitas akademika UGM dalam memahami panduan video tutorial akses e-resources.

Hasil penelitian ini diharapkan dapat menjadi bahan masukan bagi manajemen Perpustakaan UGM tentang manfaat tutorial akses e-resources berupa video di website Perpustakaan Universitas Gadjah Mada dan sebagai masukan bagi pustakawan agar terus melakukan inovasi layanan perpustakaan.

\section{B. TINJAUAN PUSTAKA}

\section{Teori Efektivitas}

Efektif berasal dari bahasa inggris yaitu effective yang berarti berhasil (Echols, 1976). Dalam Kamus Besar Bahasa Indonesia efektif adalah dapat membawa hasil atau berhasil guna.

Efektivitas pada dasarnya berasal dari kata "efek" dan digunakan istilah ini sebagai hubungan sebab akibat. Efektivitas dapat dipandang sebagai suatu sebab dari variabel lain. Efektivitas berarti bahwa tujuan yang telah direncanakan sebelumnya dapat tercapai atau dengan kata sasaran tercapai karena adanya proses kegiatan (Pasolong, 2008).

\section{Kemas Ulang informasi}

"Information repackaging is process to repackage the analysis of consolidated information in that form which is more suitable and usable for library users. Repackaging of information in digital form or in electronic medium like $C D, D V D$, etc. in other hand repackaging of information is a physical recording, arrangement and presentation of information on a given medium and in and in a given form. The aim of repackaging is to enhance the acceptance and use of information products and the assimilation and recall of their contacts."

Pengemasan ulang informasi adalah proses untuk mengemas kembali informasi terkonsolidasi dalam bentukyang lebih cocok dan dapat digunakan untuk pengguna perpustakaan. Pengemasan ulang informasi dalam bentuk digital atau dalam media elektronik seperti CD, DVD, dll. Di sisi lain pengemasan ulang informasi adalah rekaman fisik, pengaturan dan penyajian informasi pada media tertentu dan dalam bentuk tertentu. Tujuan pengemasan ulang adalah untuk meningkatkan penerimaan dan penggunaan produk informasi serta asimilasi dan penarikan kembali kontak mereka. (Dongardive, 2013)

Menurut (Maryati, 2014) kemasan informasi adalah kumpulan informasi yang disajikan dalam bentuk baru yang lebih mudah untuk digunakan, difahami, diserap, dan bahkan diadopsi oleh pengguna. Dengan penyebaran informasi yang dikemas dengan tepat dapat membantu menyelesaikan permasalahan yang dihadapi oleh pengguna. Penyebaran informasi yang baik berlangsung dari hulu ke hilir. Ini artinya informasi dapat sampai dari penghasil informasi ke semua lapisan pengguna informasi. Ada tiga faktor yang mempengaruhi penyebaran informasi yaitu konten, saluran komunikasi, dan pengguna. Konten informasi yang dikemas dengan baik merupakan media yang efektif dalam melakukan penyebaran informasi.

Selain itu menurut (Dongardive, 2013) juga mengemukakan bahwa fungsi kemas ulang informasi adalah : 1) Sebagai alat untuk menyimpan informasi 2) Sebagai penyortir informasi berguna 
Pengembangan Media Sosialisasi Akses e-resources ... (Natalia A., D. \& Nurhastuti, D.)

yang sistematis dan selektif. 3) Sebagai sarana untuk transmisi informasi yang lebih luas dan pengiriman.

4) Sebagai alat terjemahan. 5) Sebagai peluang untuk aplikasi praktis penelitian hasil. 6) Sebagai sarana untuk mempromosikan pengiriman yang relevan informasi.

\section{E-resources}

E-resources represent an increasingly important component of the collection-building activities of libraries. The guide concentrates mainly on academic and research library purposes, but nonetheless will be of high value to many types of libraries. "Electronic resources" refer to those materials that require computer access, whether through a personal computer, mainframe, or handheld mobile device. They may either be accessed remotely via the Internet or locally. Some of the most frequently encountered types are:

1. E-journals

2. E-books

3. Full-text (aggregated) databases

4. Indexing and abstracting databases

5. Reference databases (biographies, dictionaries, directories, encyclopaedias, etc.)

6. Numeric and statistical databases

7. E-images

8. E-audio/visual resources

E-resources dalam definisi di atas yang tertuang dalam panduan yang diterbitkan oleh IFLA (Díaz-Jatuf, 2013) menyebutkan bahwa e-resources merupakan komponen yang penting dari suatu kegiatan pengadaan koleksi perpustakaan. Sumber daya elektronik adalah bahan koleksi perpustakaan yang merujuk pada bahan-bahan koleksi yang memerlukan akses komputer, baik melalui komputer pribadi, mainframe, atau perangkat seluler genggam. Koleksi tersebut bisa diakses dari jarak jauh baik melalui internet atau secara lokal. Beberapa yang paling sering ditemui jenisnya adalah:
1. Jurnal elektronik

2. E-book

3. Database teks lengkap (teragregasi)

4. Pengindeksan dan abstrak database

5. Referensi basis data (biografi, kamus, direktori, ensiklopedia, dll.)

6. Basis data numerik dan statistik

7. E-gambar

4. Sumber daya e-audio / visual

E-resources dalam definisi di atas menunjukan bahwa pada semua koleksi Perpustakaan yang membutuhkan akses komputer baik melalui komputer personal (Personal Computer), mainframe, atau perangkat mobile (handphone). Hal ini menunjukkan bahwa setiap sumber informasi atau sumber daya informasi yang aksesnya melalui perangkat komputer atau perangkat mobile, maka dapat dinamakan sebagai sumber daya elektronik atau e-resources.

\section{Video Tutorial}

Video tutorial berasal dari dua kata yaitu video dan tutorial. Dalam Kamus Besar Bahasa Indonesia video berarti: (1) bagian yang memancarkan gambar pada pesawat televisi; (2) rekaman gambar hidup atau program televisi untuk ditayangkan lewat pesawat televisi (Pusat Bahasa, 2011). Sedangkan kata tutorial berarti: (1) Pembimbingan kelas oleh seorang pengajar (tutor) untuk seorang mahasiswa atau sekelompok kecil mahasiswa; (2) pengajaran tambahan melalui tutor, (3) buku, film, program komputer yang memberikan informasi praktis masalah tertentu, (4) berkenaan dng tutor (Pusat Bahasa, 2011).

Video tutorial dalam definisi diatas dapat diartikan sebagai bagian yang memancarkan gambar atau video atau program komputer yang dibuat dalam rangka memberikan informasi praktis tentang topik tertentu. 


\section{METODE PENELITIAN}

Penelitian ini adalah penelitian deskriptif dengan metode kuantitatif. Penelitian ini dilakukan di Universitas Gadjah Mada. Teknik pengambilan sampel penelitian ini yaitu dengan probability sampling, terhadap sivitas akademika UGM. Probability sampling adalah teknik pengambilan sampel yang memberikan peluang yang sama bagi setiap unsur (anggota) populasi untuk dipilih menjadi anggota sampel. Sampel di ambil secara acak atau Simple Random Sampling. Simple Random Sampling adalah rancangan yang paling sederhana dan bisa disebut juga random murni (Machfoedz, 2018). Ukuran sampel dalam penelitian ini sebanyak 155 dari 47.689 mahasiswa pada 4 kluster di UGM (UGM dalam angka, 2019) jumlah sampel tersebut merujuk pendapat Roscoe dalam Sugiyono (2011) bahwa ukuran sampel yang layak dalam penelitian adalah antara 30 sampai dengan 500 .

Subyek penelitian adalah sivitas akademika Universitas Gajah Mada dengan kuisioner online yang terdiri dari tiga bagian, yaitu: identitas, butir pertanyaan, dan saran. Pengumpulan data dalam kajian ini menggunakan kuisioner, yaitu sejumlah pertanyaan tertulis yang digunakan untuk memperoleh informasi dari responden (Arikunto, 2010). Bentuk kuisioner yang digunakan adalah skala bertingkat, dimana sebuah pertanyaan diikuti oleh kolom-kolom yang menunjukan tingkatantingkatan. Studi pustaka dilakukan pada penelitian ini yaitu melalui website Perpustakaan UGM dan literatur buku untuk mendukung data yang diperlukan.

Analisis data dilakukan dengan menggunakan teknik analisis deskriptif kuantitatif, yaitu dengan menganalisis data kuantitatif yang diperoleh dari kuisioner dari sumber internal Perpustakaan UGM dan sumber eksternal Perpustakan UGM. Data kuantitatif berupa angka-angka hasil perhitungan atau pengukuran diproses dengan cara dijumlah kemudian dibandingkan dengan jumlah yang diharapkan sehingga diperoleh persentase kelayakan. (Arikunto, 2010) Dengan rumus seperti di bawah ini:

Rumus Presentase Kelayakan

$$
\text { Presentase Kelayakan \% }=\frac{\text { Skoryang di observasi }}{\text { Skoryang diharapkan }} \times 100 \%
$$

Tabel 1. Skala Presentase Kelayakan

\begin{tabular}{|c|c|}
\hline $\begin{array}{c}\text { Presentase } \\
\text { pencapaian }\end{array}$ & Interpretasi \\
\hline $76-100 \%$ & Sangat Layak \\
\hline $56-75 \%$ & Layak \\
\hline $40-55 \%$ & Cukup \\
\hline $0-39 \%$ & Kurang Layak \\
\hline
\end{tabular}

Sumber: Arikunto, 2010

Tabel skala persentase di atas untuk menentukan nilai kelayakan yang dihasilkan. Skala persentase 1 dengan persentase pencapaian 0 $39 \%$ mendapatkan interpretasi kurang layak. Skala nilai 2 dengan persentase pencapaian $40-75 \%$ mendapatkan interpretasi cukup layak. Skala nilai 3 dengan persentase pencapaian $\quad 56-75 \%$ mendapatkan interpretsi layak, dan skala nilai 4 dengan persentase pencapaian 76 - 100\% mendapatkan interpretasi sangat layak.

\section{HASIL DAN PEMBAHASAN}

\section{Pengembangan Video Tutorial}

Dalam pengembangan video, digunakan acuan metode pengembangan yang dikemukakan oleh (Villamil-Casanova, 1997) dengan proses berikut:

1. Development

Pada tahap ini, dilakukan pengumpulan materi dan pendukung materi. Pengumpulan materi dan pendukung materi dilakukan setelah menganalisis semua yang dibutuhkan. Pengumpulan materi meliputi studi pada website Perpustakaan UGM.

2. Pre production/pra produksi 
Pengembangan Media Sosialisasi Akses e-resources ... (Natalia A., D. \& Nurhastuti, D.)

Pada tahap ini dilakukan langkah langkah sebagai berikut: 1) Pemilihan konsep video yaitu video yang akan dibuat adalah video dengan alur cerita antara 2 orang mahasiswa disertai visualisasi layar komputer yang beroperasi menunjukkan langkah-langkah untuk akses e-resources Perpustakaan UGM. Pembuatan video tutorial akan dibatasi pada lingkup akses e-content yang dilanggan. Hal ini dimaksudkan agar tema yang akan disajikan sebagai acuan pengguna lebih fokus. Adapun isi materi video adalah jenis e-resources Perpustakaan UGM, cara akses e-resources, dan macam database sesuai kluster. 2) Membuat naskah atau script 3) Menentukan sumberdaya video terdiri dari produser, model dan camera person. 4) Mendata peralatan dan perlengkapan dibutuhkan untuk produksi yaitu kamera, tripod, microphone, alat perekam audio, komputer/ laptop

3. Production / produksi

Pada tahap ini dilakukan proses teknik shooting sesuai dengan konsep yang telah disusun. Shoot/gambar yang diambil akan membawa pesan, gambaran, visual sebagaimana tujuan dari pembuatan video yaitu cara akses e-resources Perpustakaan UGM

4. Post production/ pasca produksi

Pada tahap ini dilakukan proses editing bertujuan untuk menggabungkan gambar visual dari potongan adegan, mengontrol durasi waktu pada setiap scene, memberikan penekanan pada shot tertentu, membuat dan merangkai suatu cerita secara berurutan, dan menyelaraskan video dengan audio.

5. Delivery

Pada tahap ini setelah video selesai, maka yang dilakukan selanjutnya adalah menyampaikan pada responden atau subyek penelitian. Dalam tahap peyampaian ini proses yang dilakukan adalah penyebaran kuisioner dengan menggunakan google formulir disertai lampiran printscreen panduan tekstual dan video tutorial akses e-resources. Adapun alamat akses yaitu http://ugm.id/1pJ untuk sumber internal dan http://ugm.id/1pE untuk sumber eksternal.

\section{Deskripsi Hasil Uji Kelayakan}

Video tutorial yang baik, dalam proses pengembangannya memerlukan rambu-rambu untuk masing-masing pengujian kelayakan. Hasil uji kelayakan materi dari sumber internal Perpustakaan UGM: 1) Kualitas/tampilan materi, Kemudahan 2) Pengoperasian video, 3) Kemanfaatan materi dan 4) Saran.

Tabel 2. Hasil uji kelayakan sumber internal

\begin{tabular}{|c|c|c|c|c|c|c|c|c|}
\hline \multirow{2}{*}{ Aspek } & \multicolumn{4}{|c|}{ Frekuensi } & \multirow{2}{*}{$\begin{array}{c}\text { Bobo } \\
t\end{array}$} & \multirow{2}{*}{$\begin{array}{l}\mathrm{Bu} \\
\text { tir }\end{array}$} & \multirow{2}{*}{$\begin{array}{c}\text { Bobot } \\
\text { Maksi } \\
\mathrm{mal}\end{array}$} & \multirow{2}{*}{$\%$} \\
\hline & 1 & 2 & 3 & 4 & & & & \\
\hline Tampilan & 0 & 0 & 15 & 12 & 93 & 9 & 108 & 86,1 \\
\hline $\begin{array}{l}\text { Pengope } \\
\text { asian }\end{array}$ & 0 & 0 & 7 & 5 & 41 & 4 & 48 & 85,4 \\
\hline $\begin{array}{l}\text { Kemanfa } \\
\text { atan }\end{array}$ & 0 & 0 & 8 & 10 & 64 & 6 & 72 & 88,9 \\
\hline Jumt: & $\mathrm{hK}$ & selv & whan & & 198 & 19 & 228 & 86,8 \\
\hline
\end{tabular}

Sumber: Data primer diolah tahun 2019

Berdasarkan tabel 4 hasil penilaian oleh sumber internal Perpustakaan UGM, didapatkan hasil berupa (1) aspek tampilan memiliki rata-rata penilaian sebesar $86,1 \%$ sehingga pada tabel skala kriteria kelayakan termasuk dalam kategori sangat layak. (2) aspek pengoperasian memiliki rata-rata penilaian sebesar $85,4 \%$ sehingga pada tabel skala kriteria kelayakan termasuk dalam kategori sangat layak. Sedangkan (3) aspek kemanfaatan memiliki rata-rata penilaian sebesar $88,9 \%$ sehingga pada tabel skala kriteria kelayakan termasuk dalam kategori sangat layak. Sehingga didapat jumlah keseluruhan hasil uji kelayakan sebesar $86,8 \%$, dan hal ini menunjukkan bahwa video tutorial ini sangat layak dikembangkan. Berikut adalah aspek penilaian sumber internal disajikan pada grafik dibawah ini: 


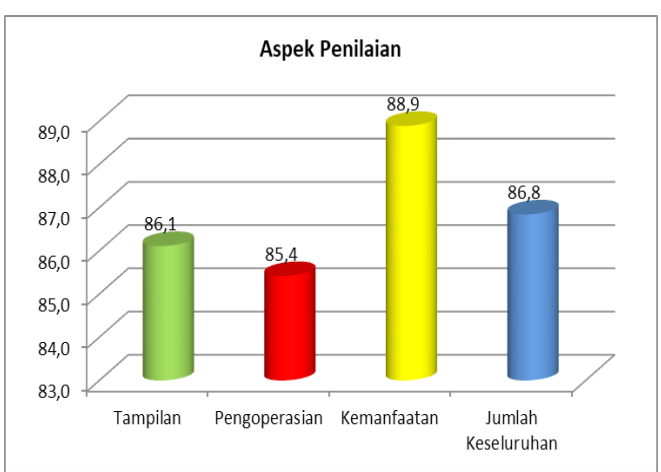

Grafik 4. Hasil penilaiaan sumber internal

Adapun saran dari sumber internal sebagai berikut:

1. Perlu diperhatikan kaidah user experience (UX) agar video lebih nyaman dilihat lagi dan komunikatif, runtut dan penjelasannya detil

2. Suasananya yang akademik

3. Disampaikan juga beberapa alternatif akses ke e-resources yg disediakan UGM, seperti mnggunakan ezproxy

4. Video yang ditampilkan kurang fokus pada content yang ditampilkan. Dialog perlu menampilkan mahasiswa yang sedang mencari content tersebut.

Untuk hasil uji kelayakan materi dari sumber eksternal Perpustakaan UGM aspek yang di uji adalah 1) Kualitas/ Tampilan 2) Pengoperasian video 3) Kemanfaatan Materi, 4) Kesulitan, dan 5) Saran. Hasil Penilaiaan kelayakan video oleh sumber eksternal Perpustakaan UGM secara rinci dijelaskan dalam grafik berikut:

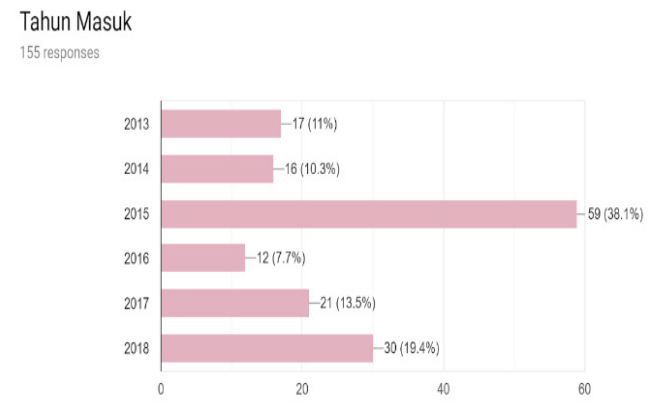

Grafik 5. Tahun masuk sumber eksternal
Grafik 5 tersebut memperlihatkan bahwa responden yang menjadi obyek penelitian adalah mahasiswa angkatan 2013, 2014, 2015, 2016, 2017 dan 2018. Serta diwakili oleh responden dari 4 kluster bidang ilmu yang ada di Universitas Gadjah Mada sesuai dengan Grafik 6.

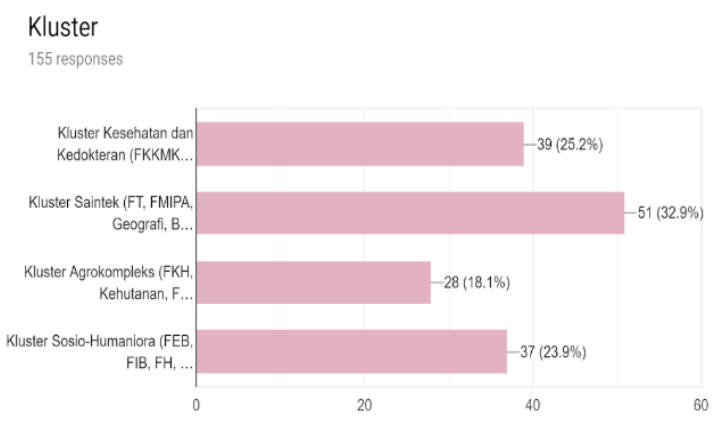

\section{Grafik 6. Kluster sumber eksternal}

Berdasarkan grafik 6 hasil penelitian oleh sumber eksternal Perpustakaan UGM, didapatkan hasil berupa (1) aspek tampilan memiliki rata-rata penilaian sebesar $83,4 \%$ sehingga pada tabel skala kriteria kelayakan termasuk dalam kategori sangat layak. (2) aspek pengoperasian memiliki rata-rata penilaian sebesar $85,3 \%$ sehingga pada tabel skala kriteria kelayakan termasuk dalam kategori sangat layak. Sedangkan (3) aspek kemanfaatan memiliki rata-rata penilaian sebesar $82,2 \%$ sehingga pada tabel skala kriteria kelayakan termasuk dalam kategori sangat layak. Sehingga didapat jumlah keseluruhan hasil uji kelayakan sebesar 83,8\%, dan hal ini menunjukkan bahwa video tutorial ini sangat layak dikembangkan. Berikut adalah aspek 
Pengembangan Media Sosialisasi Akses e-resources ... (Natalia A., D. \& Nurhastuti, D.)

penilaian sumber eksternal disajikan pada grafik dibawah ini:

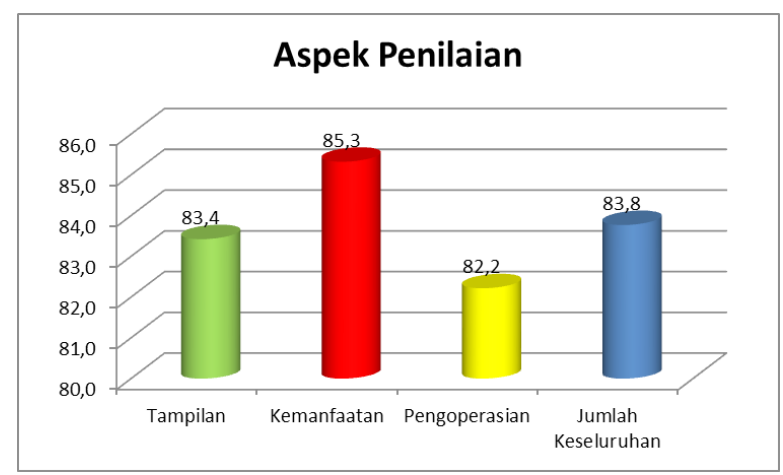

Grafik 10. Hasil penilaiaan video tutorial

Akses e-resources sumber eksternal

Bagian dari pertanyaan penelitian terkait kesulitan memahami video sebanyak 112 responden menyatakan tidak memiliki kesulitan dan 43 responden menyatakan memiliki kesulitan. Kesulitan dikelompokkan dalam dua kategori, yaitu bersifat teknis dan bersifat konten materi e-resources . Kategori bersifat teknis antara lain berkaitan dengan:

1. Audio kurang jelas

2. Tampilan web pada tayangan video meliputi ukuran huruf masih terlalu kecil

3. Penjelasan materi yang terlalu cepat Kesulitan berkaitan dengan konten materi e-resources:

1. Tidak ditemukannya jurnal yang sesuai dengan penelitian

2. Cara menggunakan dan menemukan e-resources

3. Panduan untuk mengetahui e-resources belum dibahas

Saran responden penelitian dikelompokkan dalam 4 aspek yaitu:

1. Aspek audio

Suara model dalam video diperjelas, karena backsound yang dimaksudkan sebagai pengiring agar video menarik justru mengganggu pesan yang akan disampaikan.
2. Aspek visual

Responden menyarankan untuk menampilkan video yang best practice, pencarian e-resources, ditambahkan tampilan layar penuh. Meskipun informasi ini formal, namun dapat ditambahkan animasi-animasi yang menarik.

3. Aspek tampilan

Dialog oleh model dan pemilihan bahasa perlu diperhatikan kembali.

4. Aspek durasi

Durasi video relatif cukup, namun ada yang menyatakan terlalu lama ataupun sebaliknya.

\section{E. SIMPULAN DAN SARAN}

Berdasarkan hasil penelitian dan pembahasan yang telah dibahas, maka dapat ditarik kesimpulan pembuatan video tutorial ini dinilai sangat layak oleh responden sehingga dapat digunakan sebagai sarana publikasi, karena sivitas akademika saat ini lebih cenderung memilih video sebagai media untuk memperoleh informasi. Penelitian ini juga memberikan masukan kepada perpustakaan agar mempertimbangkan kecenderungan sivitas akademika tersebut sebagai bagian dari pengembangan layanan pada sivitas akademika. Serta model kemas ulang informasi atau literasi informasi melalui video juga sangat layak diterapkan sesuai kebutuhan sivitas akademika

Pembuatan video ini merupakan tantangan sendiri bagi pustakawan untuk mengembangkan bentuk lain literasi informasi atau kemas ulang informasi kepada sivitas akademika. Yang perlu diperhatikan adalah berkaitan dengan durasi; keputusan untuk membuat short movie ataukah video tutorial sepenuhnya agar tujuan pembuatan video lebih fokus dan jelas. Serta jika video dibuat untuk memberikan paket informasi lengkap, dengan durasi panjang, maka perlu menambahkan bookmark. Hal ini dimaksudkan agar pengguna dapat memilih tayangan sesuai informasi video yang dibutuhkan. 


\section{DAFTAR PUSTAKA}

Arikunto, S. (2010). Prosedur penelitian: suatu pendekatan praktik. Jakarta: Rineka Cipta.

Díaz-Jatuf, J. (2013). Key issues for e-resource collection development: a guide for libraries. [2a.ed] / IFLA. Información, Cultura y Sociedad. Diakses 28 Juni 2019

Dongardive, P. (2013). Information repackaging in library services. International Journal, 2(11), 204-209. Retrieved from http://www.ijsr.net/ archive/v2i11/MDIwMTMOMDM=.pdf. Diakses 28 Juni 2019

Echols, J. M. (1976). Kamus inggris indonesia: an english-indonesia dictionary. Jakarta: Gramedia Pustaka Utama.

Machfoedz, I. (2018). Metodologi penelitian: kuantitatif dan kualitatif. Jakarta: Fitramaya.

Maryati, I. (2014). Kemas ulang informasi berbasis pengguna.

Pasolong, H. (2008). Teori administrasi publik. Bandung: Alfabeta.

Pusat Bahasa. (2011). Kamus besar bahasa indonesia. Jakarta: Gramedia Pustaka Utama.

Sugiyono. (2011). Statistika dalam penelitian. Bandung: Alfabeta.

UGM dalam angka. (2019). Retrieved from https:// www.ugm.ac.id/id/tentang-ugm/3679-ugm. dalam.angka. Diakses 28 Juni 2019

Villamil-Casanova, J. (1997). Multimedia production, planning and delivery. que education \& training. 